\title{
Adsorption of humic substances on ferrihydrite affects its use as iron source by plants
}

\author{
Ana de Santiago ${ }^{1}$, Ana M. García-López ${ }^{2 *}$, Ramiro Recena², María Teresa Moreno², \\ Eusebio Carmona ${ }^{2}$ and Antonio Delgado ${ }^{2}$ \\ ${ }^{1}$ Agrarian Research Institute Finca La Orden-Valdesequera, Ctra. A V km 372, 06851 Badajoz, Spain \\ ${ }^{2}$ Agroforestry Science Department, University of Seville, Ctra. Utrera km 1, 41013 Seville, Spain \\ e-mail: agarcia14@us.es
}

\begin{abstract}
Poorly crystalline Fe oxides are sources of Fe to plants. The adsorption of humic substances (HS) on these oxides alters its reactivity and stability in soils, and thus may affect Fe mobilization and uptake by plants from these compounds. This work aimed at studying how the adsorption of HS on Fe oxides affects its use as Fe source by two plant species with different Fe acquisition strategies, white lupin (Strategy I) and wheat (Strategy II). To this end, two completely randomized experiments, one with each plant, were carried out using a calcareous growing media and involving increasing amounts of HS adsorbed on ferrihydrite $\left(0,16,60\right.$, and $\left.97 \mathrm{mg} \mathrm{C} \mathrm{g}^{-1}\right)$ which was used as Fe source. The highest HS rate was the only treatment that significantly increased Fe uptake in wheat relative to control without HS. This was related to a decreased concentration of Fe in poorly crystalline oxides in the growing media. On the contrary, HS did not affect significantly Fe uptake by lupin. However, in this crop, the highest HS rate decreased the concentration of Fe in oxides relative to the lowest HS rate, without significant differences with other treatments. Thus, the effect of adsorbed HS on Fe uptake differed in two plants with different Fe acquisition strategies. The increased Fe uptake in wheat at the highest HS rate can be explained at least in part by an increased Fe mobilization from oxides by plant roots. These findings provide new insights on the role of soil organic matter on plant Fe nutrition.
\end{abstract}

Key words: iron oxides, iron nutrition, wheat, lupin, iron acquisition strategy

\section{Introduction}

Iron (Fe) is an essential micronutrient for humans and plants. Despite being an abundant element in soil, its availability to plants is usually low due to the low solubility and slow dissolution of Fe compounds (Lucena 2003, Kraemer et al. 2006, Lemanceau et al. 2009). Poorly crystalline Fe oxides, such as ferrihydrite, are supposed to be the main Fe sources for plants in soils (de Santiago and Delgado 2006, de Santiago et al. 2009, 2010, 2011). However, many chemical and biological factors in soils, such as $\mathrm{pH}$ and the complexation by organic matter, affect the availability to plants of Fe present in oxides (de Santiago et al. 2008a, García-López et al. 2013). In particular, humic sustances (HS) enhance Fe availability to plants by preventing its precipitation as Fe oxides (Schwertmann 1966, Olaetxea et al. 2018), by formation of soluble complexes (Gerke 1993, Mackowiak et al. 2001, Bocanegra et al. 2006) which can move in the soil and reach the roots increasing Fe transport (Pandeya et al. 1998, Cesco et al. 2000, Garcia-Mina et al. 2004, Chen et al. 2004, Zanin et al. 2019) and by its redox-reactive properties (Kögel-Knabner et al. 2008). Iron complexed to soluble humic substances has proven to be an efficient Fe source for plants grown in nutrient solution (Pinton et al. 1999, Cesco et al. 2002, Bocanegra et al. 2006).

The adsorption of dissolved organic matter by phyllosilicate clays and Fe/Al oxides is a relevant process explaining its mobility, retention and degradation through mineralization (Kothawala et al. 2008, Dwivedi et al. 2017). Iron oxides such as ferrihydrite strongly adsorb organic matter, which explains the accumulation of organic matter in soils (Kaiser et al. 2007). On the other hand, negatively charged functional groups in organic substances (quinones, humic acids) can interact with positively charged minerals such as iron oxides (Fink et al. 2016). This affects the reactivity and stability of Fe oxides in soils (Liu et al. 2007, Zachara et al. 2011, Amstaetter et al. 2012, Zhu et al. 2013). As mentioned above, HS improve solubility and availability of iron to plants. However, little is known about the effect of HS adsorption on the use of poorly crystalline Fe oxides as Fe sources for plants. This is very relevant to fully understand the role of soil organic matter in Fe availability to plants.

Iron oxides are sources of Fe for plants, which have different Fe acquisition strategies, i.e. strategy I (proton and organic ligands release) and strategy II (release of phytosiderophores) (Cesco et al. 2002, Colombo et al. 2012, 2014, Kulikova et al. 2017). The adsorption of HS on Fe oxides seems to alter the capacity of plant roots to 


\section{AGRICULTURAL AND FOOD SCIENCE}

A. de Santiago et al. (2020) 29: 451-459

mobilize Fe from these compounds (Och 1996). This may occur because adsorption sites for complexing agents (organic ligands or phytosiderophores) involved in Fe mobilization from oxides are occupied by HS thus decreasing their complexing and mobilization capacity. There is however no evidence of how HS affects Fe availability to plants depending on the Fe acquisition strategy. The effects of adsorption of HS on Fe oxides on Fe availability to plants may be even more relevant in basic $\mathrm{pH}$ soils, where the Fe deficiency is a frequent nutritional disorder. It can be hypothesized that adsorption of HS on Fe oxides alter Fe availability to plants, and that this effect may be different depending on the different plant Fe acquisition strategy. This will be relevant for assessing the practical consequences of preserving soil organic matter on plants Fe nutrition, and for defining more sustainable strategies for overcoming Fe deficiency in plants.

The objective of this work was to study how the adsorption of humic substances on ferrihydrite affects its use as Fe source by two species with different Fe acquisition strategy, white lupin (Strategy I) and wheat (Strategy II), grown in a calcareous growing media where Fe availability is supposed to be restricted by the basic $\mathrm{pH}$.

\section{Material and methods}

Two pot experiments were performed in a completely randomized design. One experiment was carried out using white lupin (Lupinus albus L.), with five replications and another with wheat (Triticum aestivum L.) with four replications. Both experiments involved one factor, $\mathrm{HS}$ adsorbed on ferrihydrite at different rates $(0,16,60,97 \mathrm{mg}$ of organic $\mathrm{C}$ per g of ferrihydrite). In both experiments, each replication corresponded to a cylindrical pot (polystyrene cylinder: $350 \mathrm{ml}, 5.5 \mathrm{~cm}$ diameter, $15 \mathrm{~cm}$ height) which contained $0.38 \mathrm{~kg}$ of growing medium (calcareous [2/3] and siliceous [1/3] sand coated with Fe oxide). One plant of white lupin or wheat was grown in each pot. In a former step, seeds were germinated in perlite. Fifteen days after the germination, plants were transplanted to pots. The experiments were carried out under controlled conditions in a growing chamber (photoperiod of $14 \mathrm{~h}$, a $25 / 23{ }^{\circ} \mathrm{C}$ day/night temperature, $65 \%$ relative humidity, and $22 \mathrm{~W} \mathrm{~m}^{-2}$ light intensity) for 21 days in the case of lupin and 27 in the case of wheat. A Fe-free Hoagland-type nutrient solution was daily applied during experiment (all concentrations in mmol I-1): $\mathrm{MgSO}_{4}(4), \mathrm{Ca}\left(\mathrm{NO}_{3}\right)_{2}(5), \mathrm{KNO}_{3}(5), \mathrm{KH}_{2} \mathrm{PO}_{4}(2), \mathrm{H}_{3} \mathrm{BO}_{3}(0.092), \mathrm{MnCl}_{2}(0.0018), \mathrm{CuSO}_{4}$ (0.0016), $\mathrm{ZnSO}_{4}(0.0025)$, and $\mathrm{H}_{2} \mathrm{MoO}_{4}$ (0.0023). The $\mathrm{pH}$ value of the nutrient solution was 6.5.

The growing medium was the same in both experiments, siliceous sand ( $>99 \%$ quartz) and calcareous sand ( $>99.5$ $\left.\% \mathrm{CaCO}_{3}\right)$, mixed in order to mimic a calcareous soil. Both materials were sieved between 0.5 and $1 \mathrm{~mm}$ in order to get an optimal aeration and hydraulic conductivity in the growing medium. Siliceous sand was washed with $\mathrm{Na}_{2} \mathrm{CO}_{3}$ before using according to the procedure of de Santiago and Delgado (2006) in order to remove the initial content in Fe oxides. After that, siliceous sand was coated with ferrihydrite as described by Rahmatullah and Torrent (2000). All the siliceous sand used in pots was coated with ferrihydrite in such a way that the final amount of citrate-ascorbate extractable Fe (CA-Fe) in each pot was $70 \mathrm{mg}$ (185 mg kg-1 of growing media; $260 \mathrm{mg} \mathrm{kg}^{-1} \mathrm{of}^{-}$ citrate-bicarbonate-dithionite extractable Fe in the media). This extraction is specific for the most poorly crystalline Fe oxides and it is usually related to chlorophyll content of plants (de Santiago and Delgado 2006). All CA-Fe was considered to be associated with ferrihydrite. The concentration of Fe in the growing media was selected on the grounds of previous evidences by de Santiago et al. (2009).

Humic substances (HS) were extracted from a commercial liquid mixture of humic and fulvic acids from leonardite (Solfer humicos ${ }^{\circledR}$, Valencia, Spain) according to procedure of Stevenson (1994). Extracted HS were dialysed until the $\mathrm{EC}$ was $<0.2 \mathrm{dS} \mathrm{m}^{-1}$, and after that $\mathrm{pH}$ was adjusted to 5 with $\mathrm{HCl}$. The main properties of $\mathrm{HS}$ are described in Table 1. Elemental composition of HS was determined using a Thermo Finnigan CHN elemental analyzer (Thermo Electron, Madrid, Spain). The remaining undetermined mass was assumed as oxygen content. The ash was determined in $50 \mathrm{mg}$ of $\mathrm{HS}$ after combustion at $850^{\circ} \mathrm{C}$ for $0.5 \mathrm{~h}$. Total acidity of HS was determined according to Sierra et al. (2004). Total Fe in the HS was determined by atomic absorption spectroscopy after digestion with concentrated $\mathrm{HNO}_{3}$ in closed teflon containers at $130{ }^{\circ} \mathrm{C}$ during $15 \mathrm{~min}$ in a microwave oven (Milestone, provided by Gomensoro, Madrid, Spain). Spectroscopy study was performed according to Shirshova et al. (2006) in order to characterize HS. This was done by measuring the specific spectral absorbances at $254 \mathrm{~nm}$ per unit of dissolved C in $0.1 \mathrm{~N} \mathrm{NaOH}(A)$, determining the ratio of measured spectral absorbances at $254 \mathrm{~nm}(E 2)$ and $436 \mathrm{~nm}(E 3)$, and the ratio of measured spectral absorbances at $465 \mathrm{~nm}(E 4)$ and $665 \mathrm{~nm}(E 6)$. E2 can be used as a surrogate measurement for aromaticity and the E4/E6 ratio an indication of molecular size, the ratio decreasing with increasing molecular size (de Santiago et al. 2010). Molecular weight (MW) distribution was studied according to Xu et al. (2006) using ultrafiltration membranes of different pore size. Adsorbed HS in the pots were always below the threshold value for phytotoxic effects $\left(0.06 \mathrm{~g} \mathrm{~kg}^{-1}\right.$ growing medium, de Santiago et al. $\left.2008 \mathrm{~b}\right)$. 


\begin{tabular}{|c|c|c|c|c|c|c|c|c|c|c|c|c|c|}
\hline \multirow[b]{2}{*}{ C } & \multirow[b]{2}{*}{$\mathrm{H}$} & \multirow[b]{2}{*}{$\mathrm{N}$} & \multirow[b]{2}{*}{$\mathrm{O}$} & \multirow[b]{2}{*}{ Ash } & \multirow[b]{2}{*}{ Total acidity ${ }^{\mathrm{a}}$} & & \multirow{3}{*}{$\begin{array}{c}\mathrm{A}^{\mathrm{b}} \\
\mathrm{Lg}^{-1} \mathrm{~cm}^{-1}\end{array}$} & \multirow[b]{2}{*}{$E 2 / E 3^{b}$} & \multirow[b]{2}{*}{$E 4 / E_{6}{ }^{\mathrm{b}}$} & \multicolumn{4}{|c|}{ Molecular weight distribution $(\mathrm{KDa})^{\mathrm{c}}$} \\
\hline & & & & & & & & & & $15-30$ & $30-50$ & $50-100$ & $>100$ \\
\hline & & $\%$ & & & $\mathrm{Eq} \mathrm{H}^{+} \mathrm{kg}^{-1}$ & $\mathrm{~g} \mathrm{~kg}^{-1}$ & & & & \multicolumn{4}{|c|}{$\%$ of total organic C } \\
\hline 41.7 & 4.5 & 0.7 & 52.9 & 0.2 & 7.5 & 0.11 & 117 & 4.5 & 4.5 & 25.3 & nd & 12.5 & 62.2 \\
\hline
\end{tabular}

Adsorption of HS on ferrihydrite-coated sand was performed as described by Kaiser et al. (2007). To this end, suspensions of ferrihydrite coated sand with concentrations of HS ranging from 10 to $100 \mathrm{mg} \mathrm{Cl}^{-1}$ were used to adsorb different quantities of HS on ferrihydrite. The suspension was shaken manually every so often, and its $\mathrm{pH}$ fine-tuned to 7.8. Concentration of HS in solution after the sorption process was determined through the relationship between HS concentration and the absorbance at $254 \mathrm{~nm}$, and the adsorbed HS was calculated as the difference of the HS initially present in the suspension and that at the end of the adsorption procedure. It was found that the ultraviolet spectra of HS were not modified after adsorption on Fe oxides (Reiller et al. 2006). Peak around $1380 \mathrm{~cm}^{-1}$ in the infrared spectra of ferrihydrite-coated sand with HS was characteristic of the Fe (III)-humate complexes. This revealed that HS was bound to the oxide surface by carboxilate groups (symmetric stretching in COO-groups, C-H and OH deformation) (Fu and Quan 2006, Boguta et al. 2019)

Chlorophyll meter readings (Minolta Soil Plant Analysis Development -SPAD- index) were taken at the end of each experiment in triplicate in the last totally expanded leaf of lupins and in the flag leaf of wheat using a Minolta SPAD-502 (Minolta Camera Co, Ltd., Osaka, Japan). Specific correlation between SPAD units and leaf chlorophyll content was previously checked for each plant (Chlorophyll $\left[\mathrm{mg} \mathrm{kg}^{-1}\right.$ fresh weight $]=0.3 ; \mathrm{SPAD}-0.48 ; \mathrm{R}^{2}=$ $0.85 ; p<0.001, \mathrm{n}=18$ for lupin, and Chlorophyll = SPAD/136, $\mathrm{R}^{2}=0.91, p<0.001, \mathrm{n}=22$ for wheat). At the end of the experiments, the apoplastic Fe concentration in roots was analysed according to Bienfait et al. (1985). After that, plants were harvested. Then, shoots and roots of lupins and wheats were separated and dried in a forcedair oven at $65^{\circ} \mathrm{C}$ until constant weight $(48 \mathrm{~h}$ ), i.e., dry matter (DM) content was obtained. Dry plant material was milled to pass a 1-mm screen prior to the mineralization of an aliquot of $0.5 \mathrm{~g}$ with $\mathrm{HNO}_{3}$ in teflon containers in a microwave oven (Milestone, provided by Gomensoro, Madrid, Spain). In the resulting digest, Fe concentration was determined by atomic absorption spectrometry.

Fe was analysed in the growing media at the end of the experiments in order to study its availability and main fractions. To this end, citrate-ascorbate (CA), citrate-bicarbonate-dithionite (CBD), and hydroxylamine extractions (de Santiago and Delgado 2006) were carried out. CA extraction involved the use of $2 \mathrm{M} \mathrm{Na}$ citrate $+0.05 \mathrm{M}$ ascorbate (CA-Fe) at $\mathrm{pH} 6$, which dissolves poorly crystalline Fe oxides. CBD extraction was performed to dissolve all the Fe oxides present in the growing media, and involved the use of $0.27 \mathrm{M} \mathrm{Na}$ citrate $+0.11 \mathrm{M} \mathrm{NaHCO}_{3}+2 \% \mathrm{Na}$ dithionite (CBD-Fe) at $\mathrm{pH} 8.5$; in both cases at a growing media:extractant ratio of 1:40. Hydroxylamine extraction was deemed by de Santiago and Delgado (2006) a more accurate Fe availability index than other classical extractions such as those based in the use of complexing agents.

The effect of increasing amounts of adsorbed HS on ferrihydrite on the different measured variables was assessed by analysis of variance (ANOVA), using the General Linear Model (GLM) and regressions, in the software Statgraphics Plus 5.1 (StatPoint 2000). Differences between means were assessed with LSD test at $p<0.05$. Normality and homoscedasticity were always previously checked by using the Smirnoff-Kolmogorov and Levene test, respectively (Acutis et al. 2012), and data transformed when either one or both tests were not passed.

\section{Results}

The amount of HS adsorbed on the Fe oxides present in the growing media did not affect chlorophyll content and DM yield of lupins or wheat (Table 2). Total Fe uptake by lupins and wheat was affected by HS adsorbed on the oxides present in the media (Fig. 1). In the case of lupins, total Fe uptake by plants at the highest HS rate $\left(97 \mathrm{mg} \mathrm{C} \mathrm{g}^{-1}\right)$ adsorbed on ferrihydrite was greater than at the lowest rate $\left(16 \mathrm{mg} \mathrm{C} \mathrm{g}^{-1}\right)$; however, non-significant differences were observed with control without HS (Fig. 1). In the case of wheat, the concentration of Fe in roots, and the total amount of Fe in roots and the whole plant were significantly enhanced by HS at the highest rate when compared with other treatments (Table 2). 


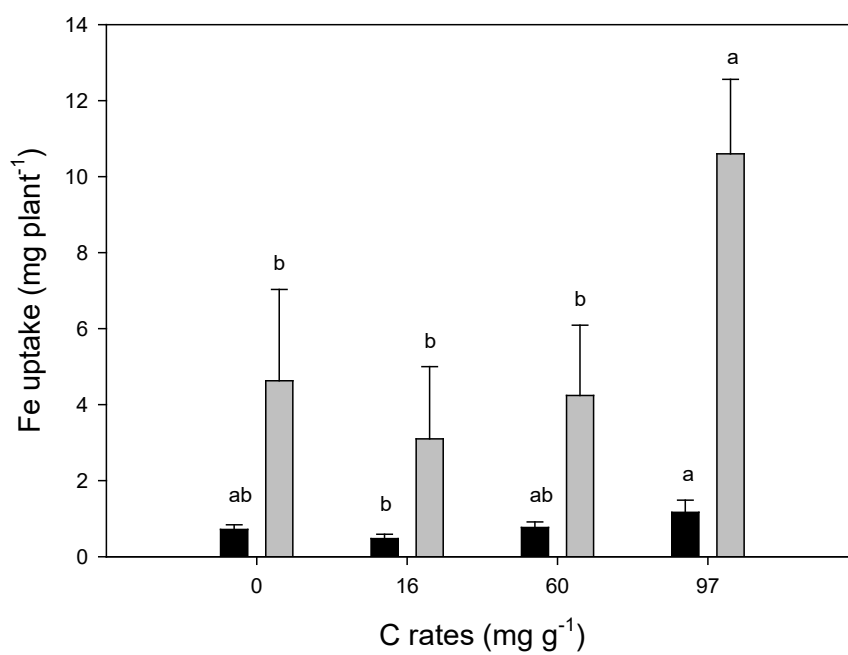

Fig. 1. Effect of the different rate of Fe-HS on total Fe uptake by lupin (black columns) and wheat (grey columns). One-way ANOVA was performed for each plant independently. Means with different letter were significantly different as per LSD test at $p<0.05$; Error bars indicate one standard error.

Table 2. Effect of different amounts of humic substances adsorbed on ferrihydrite on the chlorophyll meter readings (SPAD), dry matter (DM) yields, Fe concentration in aerial parts and roots, and the total amount of Fe in aerial parts and roots of lupins and wheat grown on a calcareous growing medium

\begin{tabular}{|c|c|c|c|c|c|c|c|c|c|c|c|c|c|c|}
\hline \multirow{3}{*}{$\begin{array}{c}\text { Rate }^{+} \\
\mathrm{mg} \mathrm{C}^{-1}\end{array}$} & \multicolumn{7}{|c|}{ Lupin } & \multicolumn{7}{|c|}{ Wheat } \\
\hline & \multirow[b]{2}{*}{ SPAD } & \multirow[b]{2}{*}{$\begin{array}{c}\text { DM } \\
\text { aerial } \\
\text { parts }\end{array}$} & \multirow[b]{2}{*}{$\begin{array}{l}\mathrm{DM} \\
\text { roots }\end{array}$} & \multicolumn{2}{|c|}{$\begin{array}{c}\mathrm{Fe} \\
\text { concentration }\end{array}$} & \multicolumn{2}{|c|}{ Total Fe } & \multirow[b]{2}{*}{ SPAD } & \multirow[b]{2}{*}{$\begin{array}{c}\text { DM } \\
\text { aerial } \\
\text { parts }\end{array}$} & \multirow[b]{2}{*}{$\begin{array}{l}\text { DM } \\
\text { roots }\end{array}$} & \multicolumn{2}{|c|}{$\begin{array}{c}\mathrm{Fe} \\
\text { concentration }\end{array}$} & \multicolumn{2}{|c|}{ Total Fe } \\
\hline & & & & $\begin{array}{l}\text { Aerial } \\
\text { parts }\end{array}$ & Roots & $\begin{array}{c}\text { Aerial } \\
\text { parts }\end{array}$ & Roots & & & & $\begin{array}{l}\text { Aerial } \\
\text { parts }\end{array}$ & Roots & $\begin{array}{l}\text { Aerial } \\
\text { parts }\end{array}$ & Roots \\
\hline & $\begin{array}{c}\text { Arbitrary } \\
\text { units }\end{array}$ & \multicolumn{2}{|c|}{ g plant $^{-1}$} & \multicolumn{2}{|c|}{$\mathrm{mg} \mathrm{kg}^{-1}$} & \multicolumn{2}{|c|}{$\mu \mathrm{g}$ plant $^{-1}$} & $\begin{array}{l}\text { Arbitrary } \\
\text { units }\end{array}$ & \multicolumn{2}{|c|}{ g plant $^{-1}$} & $\begin{array}{c}\mathrm{mg} \\
\mathrm{kg}^{-1}\end{array}$ & $\mathrm{~g} \mathrm{~kg}^{-1}$ & $\begin{array}{c}\mu \mathrm{g} \\
\text { plant }^{-1}\end{array}$ & $\begin{array}{c}\mathrm{mg} \\
\text { plant }^{-1}\end{array}$ \\
\hline 0 & 48.25 & 1.24 & 0.67 & 111 & 848 & 138 & 579 & 39.50 & 2.03 & 1.32 & 189 & $3.27 \mathrm{~b}$ & 391 & $4.16 \mathrm{~b}$ \\
\hline 16 & 44.00 & 1.17 & 0.52 & 77 & 756 & 88 & 387 & 40.75 & 1.89 & 1.22 & 170 & $2.21 \mathrm{~b}$ & 339 & $2.77 b$ \\
\hline 60 & 47.50 & 1.32 & 0.70 & 131 & 811 & 174 & 596 & 38.50 & 1.94 & 1.04 & 121 & $3.42 b$ & 226 & $4.02 \mathrm{~b}$ \\
\hline 97 & 52.25 & 1.15 & 0.67 & 301 & 1235 & 306 & 860 & 38.25 & 2.06 & 1.28 & 189 & $7.93 a$ & 390 & $10.21 \mathrm{a}$ \\
\hline ANOVA & NS & NS & NS & NS & NS & NS & NS & NS & NS & NS & NS & $*$ & NS & * \\
\hline
\end{tabular}

$\dagger=$ Rate in mg C per g of ferrihydrite; Means; means in the same column followed by different letters are significantly different according to the LSD test at $p<0.05 ; \mathrm{DM}=$ dry matter; NS = not significant; ${ }^{*}=$ significant at $p<0.05$

Adsorbed HS did not affect apoplastic Fe in roots of lupins (Fig. 2). In wheat, apoplastic Fe in the control without HS rate was significantly greater than those observed at all HS rates (Fig. 2).

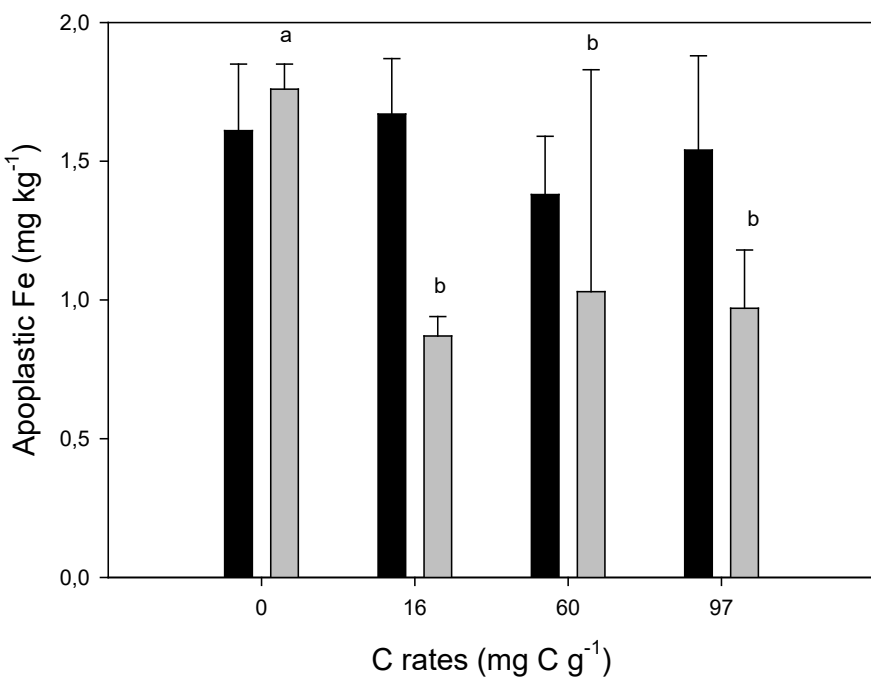

Fig. 2 Effect of the different rate of Fe-HS on concentration of apoplastic $\mathrm{Fe}$ in roots of lupin (black columns) and wheat (grey columns). One-way ANOVA was performed for each plant independently. Means with different letter were significantly different as per LSD test at $p<0.05$. Error bars indicate one standard error. 


\section{AGRICULTURAL AND FOOD SCIENCE}

A. de Santiago et al. (2020) 29: 451-459

Overall, lupins promoted a significant decrease of CA- and CBD-extractable Fe after the experiment (Fig. 3b and 3c) when compared with initial contents (185 and $257 \mathrm{mg} \mathrm{Fe} \mathrm{kg}{ }^{-1}$ of CA- and CBD-Fe, respectively). Amounts of Fe mobilized from the media were much higher than those extracted by lupin plants. By contrast, the effect of wheat growth on the contents of extractable Fe was, on average, almost negligible in comparison to initial contents.

For lupin, CBD-Fe significantly decreased at the highest HS rate when compared with control (Fig. 3c). The lowest CBD-Fe was observed in the treatment with the highest Fe uptake by lupins. However, CA-Fe, mostly ascribed to poorly crystalline Fe oxides, was not significantly affected by HS with lupin (Fig. 3b). For wheat, the Fe availability index (hydroxylamine extractable) and CA-Fe was affected by HS adsorption (Fig. 3a). This reveals an effect of HS ascribed only to poorly crystalline Fe oxides in wheat. Citrate-ascorbate extractable Fe after wheat crop was lower at the highest HS rates than with the two lowest rates, which evidences an increased mobilization of Fe from ferrihydrite at the highest rate (Fig. $3 \mathrm{~b}$ ). This is consistent with the observed effect of HS on the total Fe uptake by wheat plants since the lowest CA-Fe was observed in treatment showing the highest Fe uptake by plants.
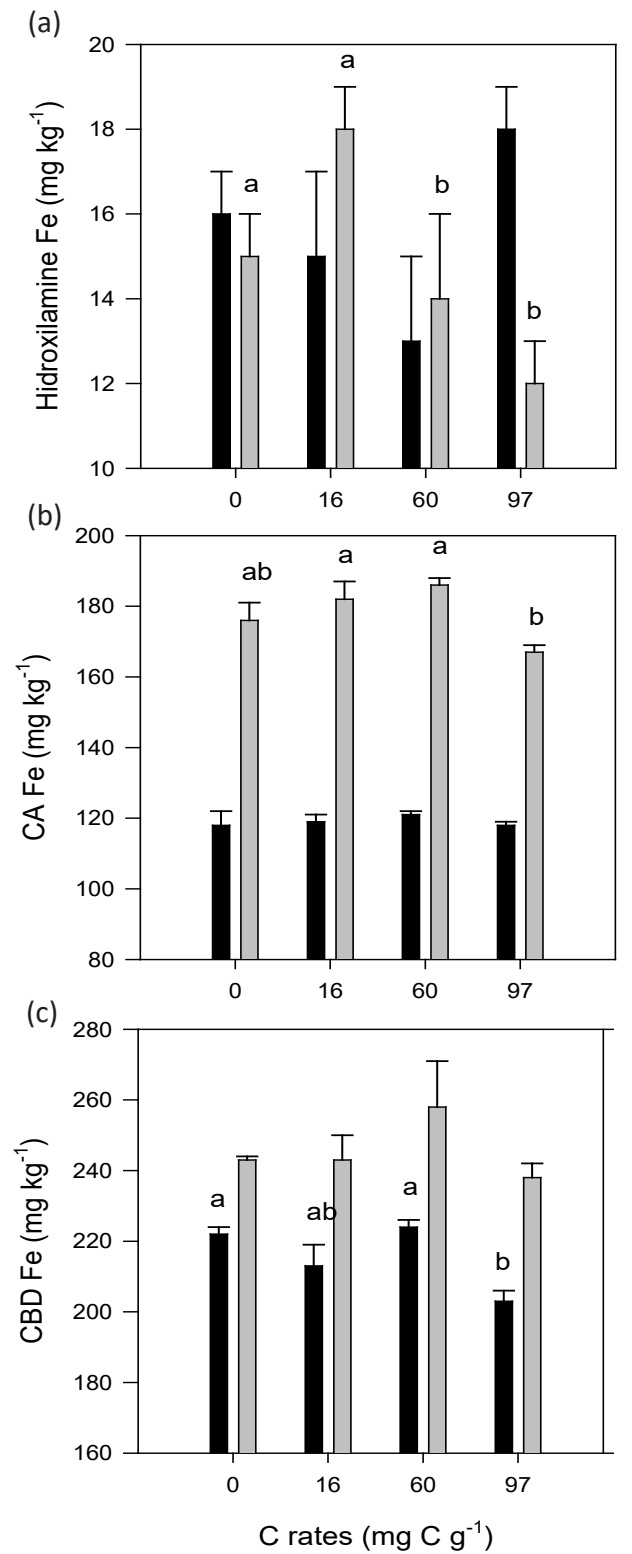

Fig. 3. Effect of the different rate of Fe-HS on Fe extractable with hydroxylamine in the growing medium (a), on Fe extractable with citrate ascorbate (CA-Fe) in the growing medium (b), and on Fe extractable with citrate bicarbonate dithionite (CBD-Fe) in the growing medium (c) of lupin plants (black columns) and wheat plants (grey columns). Oneway ANOVA was performed for each plant independently. Means with different letter were significantly different as per LSD test at $p<0.05$. Error bars indicate one standard error. 


\section{AGRICULTURAL AND FOOD SCIENCE}

A. de Santiago et al. (2020) 29: 451-459

\section{Discussion}

Overall, the adsorption of HS on Fe oxides acting as a Fe source in growing media affected the Fe availability to plants. However, this effect was different depending on the cultivated plant. In the case of lupin, there was not a significant effect of HS on Fe uptake. In contrast, the highest HS rate increased total Fe uptake by wheat when compared with control without HS and the other HS rates (Fig. 1). This effect was mainly ascribed to an increased Fe accumulation in roots with the highest HS rate. Humic substances decreased apoplastic Fe in wheat at the highest rate (Fig. 2). This may reveal an increased transport of Fe from apoplast to symplast with $\mathrm{HS}$ adsorbed on Fe oxides. This implies an increased physiological active fraction of absorbed Fe in wheat roots. In this plant, Fe concentration in roots also increased at the highest HS rate relative to the other treatments (Table 2). The increased Fe concentration and accumulation in the roots of wheat at the highest HS rate was partly justified by the increased mobilization of Fe from the medium. This mobilization is evidenced by the decreased hydroxylamine and CA extractable Fe at the highest HS rate (Figs. 3a and 3b). However, Fe concentration and accumulation in aerial parts were not significantly different between treatments in both plants. Thus, the increased Fe uptake by wheat is only reflected in an increased accumulation in roots, without increased translocation to aerial parts. This agrees Cieschi et al. (2019) who found that an increase in iron humate concentration in the rhizosphere might cause a decrease in the transcription level of the genes involved in the iron transport, explaining a decreased transport from roots to shoots. Different plant species have different Fe acquisition mechanisms and response to Fe deficiencies (Bienfait 1988, Brown and Jolley 1989, Shi et al. 1993). It seems possible that these different results in lupin and wheat are due to the differences in the Fe acquisition mechanisms in lupin (Strategy I) and wheat (Strategy II).

Humic substances adsorbed on Fe oxides in the growing media affected the contents of extractable Fe after the experiments. In lupin, the decrease in the CA-Fe was roughly equivalent to that of CBD-Fe, thus revealing that most of the oxides dissolved were poorly crystalline (ferrihydrite). These results are consistent with those of other studies and suggest that the exudation of large amounts of organic acids such as citric by lupines roots (Dinkelaker et al. 1989, Egle et al. 2003) is very effective promoting the dissolution of Fe compounds in soil (Gerke 1993, 1997, 2010, Tiping 2002). In lupin, CBD-Fe decreased at the highest HS. It is well known that HS and organic substances produced by plants are involved in the dissolution of Fe minerals (Cesco et al. 2000, Violante et al. 2003, Mimmo et al. 2014). In addition, HS can increase the release of root exudates (Canellas et al. 2019) thus increasing Fe mobilization from soil. Thus, this effect of HS promoting the release of Fe from oxides may improve the response of plants to Fe deprivation. However, this increased mobilization of Fe at the highest HS rate when compared with other HS rates did not result in an increased Fe uptake by lupin. This means that, in addition to Fe mobilization, other factors affecting Fe absorption and transport, such as the functioning of the Fe(III)-chelate reductase in membranes are crucial explaining the effect of HS on Fe uptake by lupin.

Iron requirement for wheat was covered with a very small Fe release from the ferrihydrite present in the media as revealed by the small decrease in CA-Fe when compared with initial contents in the growing media. This is consistent with the well-known Fe acquisition strategy of gramineous plants (Strategy II) based on highly selective Fe-complexing compounds (siderophores). Small amounts of Fe released by siderophores are enough to cover plant requirement (Kraemer et al. 2006, Ahmed and Holmström 2014, Poggenburg et al. 2018). Cesco et al. (2000) observed that the acquisition of Fe from ferrihydrite is guaranteed by the siderophore efflux. The stability of the complexes formed between Fe and siderophores are much higher than the stability of the humic-Fe complexes; this makes humic-associated Fe to be an easily available Fe source for strategy II plant species such as wheat (Gerke 2010). This contributes to explain the increased Fe uptake by wheat at the highest HS rate, which is consistent with the decreased CA-Fe and hydroxylamine extractable Fe at this HS rate.

The effect of the highest rate of HS increasing Fe oxides mobilization with lupin was not only ascribed to poorly crystalline Fe oxides since the significant decrease in extractable Fe was only observed with CBD, which is supposed to dissolve poorly crystalline and crystalline Fe oxides. This effect of HS on extractable Fe is consistent with previous results by Gerke (1993) showing that low molecular weight acids, such those excreted by lupin roots (Dinkelaker et al. 1989), were more effective releasing Fe from Fe oxides bound to HS. The decrease in CBD extractable Fe with lupin was much higher than total Fe in plants. This likely reveal that only a part of mobilized Fe was taken up by plants, and also that a part of Fe initially present in the oxide may precipitate in forms not extractable by the action a strong reductant such as dithionite, or may be lost by leaching if present as soluble Fe-complexes. By contrast, the Fe availability index (hydroxylamine extractable) and CA-Fe decreased with HS adsorption in wheat (Figs. $3 a$ and $3 b$ ). This likely reveal a more selective mobilization of Fe from poorly crystalline Fe oxides, to which hydroxylamine extractable Fe is related (de Santiago and Delgado 2006). 


\section{AGRICULTURAL AND FOOD SCIENCE}

A. de Santiago et al. (2020) 29: 451-459

Several works have demonstrated iron uptake by plant with the Fe:HS ratio lower than that obtained in our study (Kulikova et al. 2017, Cieschi et al. 2019). Nevertheless, at the highest HS rate, concentration of HS in equilibrium with adsorbed HS must be greater than at other rates. This soluble HS have proved to increase the mobilization of Fe from oxides (Cesco et al. 2000). Also, HS enhance the development and acidification capacity of roots (Trevisan et al. 2010), and Fe-HS complexes are natural substrates for the membrane Fe (III)-chelate reductase and stimulate the proton release promoting the Fe acquisition by strategy I plants (de Santiago and Delgado 2007, Cieschi et al. 2019). An enhanced acidification and reductant capacity of roots can positively contribute to an increased Fe mobilization from oxides which is evidenced by the decrease in different Fe fractions in the growing media after crop. This may explain the increased Fe uptake by wheat with the highest HS rate. In agreement with previous findings, concentration and accumulation of Fe in plants were considered in a nontoxic range and enough for an adequate growth (Marschner 1995). Similar values were reported by Shane et al. (2008) and de Santiago et al. (2010) in previous studies. This may explain the lack of effect of HS treatments on DM yield and SPAD readings.

\section{Conclusions}

As hypothesized, the adsorption of HS on ferrihidryte affected the mobilization of Fe from poorly crystalline oxides measured as the decrease of extractable Fe in the growing media after crop. The effect was different for lupin and wheat, with different Fe acquisition mechanisms. The highest HS rate $\left(97 \mathrm{mg} \mathrm{C} \mathrm{g}^{-1}\right)$ promoted increased Fe uptake in wheat relative to control and other HS rates. In lupin, the highest HS rate increased Fe mobilization when compared to the lowest rate, without significant differences with the control without HS. These differences were not reflected in differences in Fe uptake by lupin. The effect of HS on Fe uptake by plants can be explained at least in part by an increased mobilization of Fe from oxides by plant roots. These findings enhance our understanding of the role of soil organic matter on plant Fe nutrition.

\section{Acknowledgements}

This study was funded by the Spanish Ministry of Education and Science and by the Regional Development Funds of the European Union through the National Research, Development and Innovation Program (Plan Nacional I $+d+i$, Project AGL2008-05053-CO2). Experimental facilities were provided by the Agricultural Research Service of the University of Seville (SIA).

\section{References}

Acutis, M., Scaglia, B. \& Confalonieri, R. 2012. Perfunctory analysis of variance in agronomy, and its consequences in experimental results interpretation. European Journal of Agronomy 43: 129-135. https://doi.org/10.1016/j.eja.2012.06.006

Ahmed, E. \& Holmström, S.J. 2014. Siderophores in environmental research: roles and applications. Microbial Biotechnology 7: 196-208. https://doi.org/10.1111/1751-7915.12117

Amstaetter, K., Borch, T. \& Kappler, A. 2012. Influence of humic acid imposed changes of ferrihydrite aggregation on microbial Fe(III) reduction. Geochimica et Cosmochimica Acta 85: 326-341. https://doi.org/10.1016/j.gca.2012.02.003

Bienfait, H.F., Vander, B.W. \& Mesland-Mul, N.T. 1985. Free space iron pools in roots: generation and mobilization. Plant Physiology 78: 596-600. https://doi.org/10.1104/pp.78.3.596

Bienfait, H.F. 1988., Mechanisms in Fe-efficiency reactions of higher plants. Journal of Plant Nutrition 11: 605-629. https://doi.org/10.1080/01904168809363828

Bocanegra, M.P., Lobartini, J.C. \& Orioli, G.A. 2006. Plant uptake of iron chelated by humic acids of different molecular weights. Communications in Soil Science and Plant Analysis 37: 239-248. https://doi.org/10.1080/00103620500408779

Boguta, P., D'Orazio, V., Senesi, N., Sokołowska, Z. \& Szewczuk-Karpisz, K. 2019. Insight into the interaction mechanism of iron ions with soil humic acids. The effect of the $\mathrm{pH}$ and chemical properties of humic acids. Journal of Environmental Management 245: 367-374. https://doi.org/10.1016/j.jenvman.2019.05.098

Brown, J.C. \& Jolley, V.D. 1989. Plant metabolic responses to iron- deficiency stress. BioScience 39: 546-551. https://doi.org/10.2307/1310977

Canellas, L.P., Olivares, F.L., Canellas, N.O.A., Mazzei, P. \& Piccolo, A. 2019. Humic acids increase the maize seedlings exudation yield. Chemical and Biological Technologies in Agriculture 6: 3.

Cesco, S., Nikolic, M., Römheld, V., Varanini, Z. \& Pinton, R. 2002. Uptake of ${ }^{59} \mathrm{Fe}$ from soluble ${ }^{59} \mathrm{Fe}-\mathrm{humate}$ complexes by cucumber and barley plants. Plant and Soil 241: 121-128. https://doi.org/10.1023/A:1016061003397

Cesco, S., Römheld, V., Varanini, Z. \& Pinton, R. 2000. Solubilization of iron by water-extractable humic substances. Journal of Plant Nutrition and Soil Science 163: 285-290. https://doi.org/10.1002/1522-2624(200006)163:3<285::AID-JPLN285>3.0.CO;2-Z

Chen, Y., De Nobili, M. \& Aviad, T. 2004. Stimulatory effects of humic substances on plant growth, In: Magdoff, F. \& Weil, R.R. (eds). Soil Organic Matter in Sustainable Agriculture, New York, (NY): CRC Press. p. 103-130. https://doi.org/10.1201/9780203496374.ch4 
Cieschi, M.T., Polyakov, A.Y., Lebedev, V.A., Volkov, D.S., Pankratov, D.A., Veligzhanin, A.A., Perminova, I.V. \& Lucena, J.J. 2019. Ecofriendly iron-humic nanofertilizers synthesis for the prevention of iron chlorosis in soybean (Glycine max) grown in calcareous soil. Frontier in Plant Science 10: 413. https://doi.org/10.3389/fpls.2019.00413

Colombo, C., Palumbo, G., Sellitto, V.M., Rizzardo, C., Tomasi, N., Pinton, R. \& Cesco, S. 2012. Characteristics of insoluble, high molecular weight iron-humic substances used as plant iron sources. Soil Science Society of America Journal 76: 1246-1256.

Colombo, C., Palumbo, G., He, J.Z., Pinton, R. \& Cesco, S. 2014. Review on iron availability in soil: interaction of Fe minerals, plants, and microbes. Journal of Soils and Sediments 14: 538-548. https://doi.org/10.1007/s11368-013-0814-z

de Santiago, A. \& Delgado, A. 2006. Predicting iron chlorosis of Lupinus albus L. in calcareous Spanish soils from various iron extracts. Soil Science Society of America Journal 70: 1945-1950. https://doi.org/10.2136/sssaj2005.0343

de Santiago, A. \& Delgado, A. 2007. Effects of humic substances on iron nutrition of lupin. Biology and Fertility of Soils 43: 829836. https://doi.org/10.1007/s00374-007-0191-0

de Santiago, A., Expósito, A., Quintero, J.M., Carmona, E. \& Delgado, A. 2010. Adverse effects of humic substances from different origin on lupin as related to iron sources. Journal of Plant Nutrition 33: 143-156. https://doi.org/10.1080/01904160903434220

de Santiago, A., Díaz, I., del Campillo, M.C., Torrent, J. \& Delgado, A. 2008a. Predicting the Incidence of Iron Deficiency Chlorosis from Hydroxylamine-Extractable Iron in Soil. Soil Science Society of America Journal 72: 1493-1499. https://doi.org/10.2136/sssaj2007.0366

de Santiago, A., Quintero, J.M., Carmona, E. \& Delgado, A. 2008b. Humic substances increase the effectiveness of iron sulfate and vivianite preventing iron chlorosis in white lupin. Biology and Fertility of Soils 44: 875-883. https://doi.org/10.1007/s00374$008-0272-8$

de Santiago, A., Quintero, J.M., Avilés, M. \& Delgado, A. 2009. Effect of Trichoderma asperellum strain T34 on iron nutrition in white lupin. Soil Biology and Biochemistry 41: 2453-2459. https://doi.org/10.1016/j.soilbio.2009.07.033

de Santiago, A., Quintero, J.M., Avilés, M. \& Delgado, A. 2011. Effect of Trichoderma asperellum strain T34 on iron, copper, manganese, and zinc uptake by wheat grown on a calcareous medium. Plant and Soil 342: 97-104. https://doi.org/10.1007/s11104-010-0670-1

Dinkelaker, B., Römheld, V. \& Marschner, H. 1989. Citric acid excretion and precipitation of calcium citrate in the rhizosphere of white lupin (Lupinus albus L.). Plant, Cell and Environment 12: 285-292. https://doi.org/10.1111/j.1365-3040.1989.tb01942.x

Dwivedi, D., Riley, W.J., Torn, M.S., Spycher, N., Maggi, F. \& Tang, J.Y. 2017. Mineral properties, microbes, transport, and plantinput profiles control vertical distribution and age of soil carbon stocks. Soil Biology and Biochemistry 107: $244-259$. https://doi.org/10.1016/j.soilbio.2016.12.019

Egle, K., Römer, W. \& Kellere, H. 2003. Exudation of low molecular weight organic acids by Lupinus albus L., Lupinus angustifoliu L. and Lupinus luteus L. as affected by phosphorus supply. Agronomie 23: 511-518. https://doi.org/10.1051/agro:2003025

Fink, J.R., Inda, A.V., Tiecher, T. \& Barron, V. 2016. Iron oxides and organic matter on soil phosphorus availability. Ciência e Agrotecnologia 40: 369-379. https://doi.org/10.1590/1413-70542016404023016

Fu, H. \& Quan, X. 2006. Complexes of fulvic acid on the surface of hematite, goethite, and akaganeite: FTIR observation. Chemosphere 63: 403-410. https://doi.org/10.1016/j.chemosphere.2005.08.054

García-López, A.M., Avilés, M. \& Delgado, A. 2013. Iron availability thresholds for the inoculation of cucumber with Trichoderma asperellum T34. Journal of Plant Nutrition and Soil Science 176: 867-875. https://doi.org/10.1002/jpln.201300277

García-Mina, J.M., Antolín, M.C. \& Sanchez-Diaz, M. 2004. Metal-humic complexes and plant micronutrient uptake: a study based on different plant species cultivated in diverse soil types. Plant and Soil 258: 57-68.

https://doi.org/10.1023/B:PLSO.0000016509.56780.40

Gerke, J. 1993. Solubilization of Fe (III) from humic-Fecomplexes, humic/Fe-oxide mixtures and from poorly ordered Fe-oxide by organic acids - consequences for P adsorption. Z. Pflanzenernähr Bodenk 156: 253-257. https://doi.org/10.1002/jpln.19931560311

Gerke, J. 1997. Alumnium and iron(III) species in the soil solution including organic complexes with citrate and humic substances. Z. Pflanzenernähr Bodenk 160: 427-432. https://doi.org/10.1002/jpln.19971600313

Gerke, J. 2010. Humic (Organic Matter)-Al(Fe)-Phosphate Complexes: An Underestimated Phosphate Form in Soils and Source of Plant-Available Phosphate. Soil Science 175: 417-425. https://doi.org/10.1097/SS.0b013e3181f1b4dd

Kaiser, K., Mikutta, R. \& Guggenberger, G. 2007. Increased stability of organic matter sorbed to ferrihydrite and goethite on aging. Soil Science Society of America Journal 71: 711-719. https://doi.org/10.2136/sssaj2006.0189

Kögel-Knabner, I., Guggenberger, G., Kleber, M., Kandeler, E., Kalbitz, K., Scheu, S., Eusterhues, K. \& Leinweber, P. 2008. Organomineral associations in temperate soils: integrating biology, mineralogy, and organic matter chemistry. Journal of Plant Nutrition and Soil Science 171: 61-82. https://doi.org/10.1002/jpln.200700048

Kothawala, K.N., Moore, T.R. \& Hendeshot, W.H. 2008. Adsorption of dissolved organic carbon to mineral soils: a comparison of four isotherm approaches. Geoderma 148: 43-50. https://doi.org/10.1016/j.geoderma.2008.09.004

Kraemer, S.M., Crowley, D. \& Kretzschmar, R. 2006. Geochemical aspects of phytosiderophore-promoted iron acquisition by plants. Advance in Agronomy 91: 1-46. https://doi.org/10.1016/S0065-2113(06)91001-3

Kulikova, N.A., Polyakov, A.Y., Lebedev, V.A., Abroskin, D.P., Volkov, D.S., Pankratov, D.A., Klein, O.I., Senik, S.V., Sorkina, T.A., Garshev, A.V., Veligzhanin, A.A., García-Mina, J.M. \& Perminova, I.V. 2017. Key roles of size and crystallinity of nanosized iron hydr(oxides) stabilized by humic substances in iron bioavailability to plants. Journal of Agricultural and Food Chemistry 65:11157-11169. https://doi.org/10.1021/acs.jafc.7b03955

Lemanceau, P., Bauer, P., Kraemer, S. \& Briat, J.F. 2009. Iron dynamics in the rhizosphere as a case study for analyzing interactions between soils, plants and microbes. Plant and Soil 321: 513-535. https://doi.org/10.1007/s11104-009-0039-5 


\section{AGRICULTURAL AND FOOD SCIENCE}

A. de Santiago et al. (2020) 29: 451-459

Liu, C., Zachara, J.M., Foster, N.S. \& Strickland, J. 2007. Kinetics of reductive dissolution of hematite by bioreduced anthraquinone-2,6-difulfonate. Environmental Science \& Technology 41: 7730-7735. https://doi.org/10.1021/es070768k

Lucena, J.J. 2003. Fe chelates for remediation of Fe chlorosis in Strategy I plants. Journal Plant Nutrition 26: 1969-1984. https://doi.org/10.1081/PLN-120024257

Mackowiak, C.L., GrossI, P.R. \& Bugbee, B.G. 2001. Beneficial effects of humic acid on micronutrient availability to wheat. Soil Science Society of America Journal 65: 1744-1750. https://doi.org/10.2136/sssaj2001.1744

Marschner, H. 1995. Mineral nutrition of higher plants, 2nd edn. London, UK: Academic Press. 889 p.

Mimmo, T., Del Buono, D., Terzano, R., Tomasi, N., Vigani, G., Crecchio, C., Pinton, R., Zocchi, G. \& Cesco, S. 2014. Rhizospheric organic compounds in the soil-microorganism-plant system: their role in iron availability. European Journal of Soil Science 65: 629-642. https://doi.org/10.1111/ejss.12158

Och, M. 1996. Influence of humified and on-humified natural organic compounds on mineral dissolution. Chemical Geology 132:119-124. https://doi.org/10.1016/S0009-2541(96)00046-0

Olaetxea, M., De Hita, D., García, C.A., Fuentes, M., Baigorri, R., Mora, V., Garnica, M., Urrutia, O., Erro, J., Zamarreño, A.M., Berbara, R.L. \& García-Mina, J.M. 2018. Hypothetical framework integrating the main mechanisms involved in the promoting action of rhizospheric humic substances on plant root- and shoot- growth. Appied Soil and Ecology 123:521-537. https://doi.org/10.1016/j.apsoil.2017.06.007

Pandeya, S.B., Singh, A.K. \& Dhar, P. 1998. Influence of fulvic acid on transport of iron in soils and uptake by paddy seedlings. Plant and Soil 198: 117-125. https://doi.org/10.1023/A:1004256325090

Pinton, R., Cesco, S., Santi, S., Agnolon, F. \& Varanini, Z. 1999. Water-extractable humic substances enhance iron deficiency responses by Fe-deficient cucumber plants. Plant and Soil 210: 145-157. https://doi.org/10.1023/A:1004329513498

Poggenburg, C., Mikutta, R., Liebmann, P., Koch, M. \& Guggenberger, G. 2018. Siderophore-promoted dissolution of ferrihydrite associated with adsorbed and coprecipitated natural organic matter. Organic Geochemistry 125: 177-188.

https://doi.org/10.1016/j.orggeochem.2018.09.004

Rahmatullah \& Torrent, J. 2000. Phosphorus dynamics and uptake by wheat in a model calcite-ferrihydrite system. Soil Science 165: 803-812. https://doi.org/10.1097/00010694-200010000-00005

Reiller, P., Amekraz, B. \& Moulin, C. 2006. Sorption of Aldrich humic acid onto hematite: insights into fractionation phenomena by electrospray ionization with quadrupole time-of-flight mass spectrometry. Environmental Science \& Technology 40: $2235-2241$. https://doi.org/10.1021/es0520518

Schwertmann, U. 1966. Inhibitory effect of soil organic matter on the crystallization of amorphous ferric hydroxide. Nature 212 : 645-647. https://doi.org/10.1038/212645b0

Shane, M.W., Lambers, H., Cawthray, G.R., Kuhn, A.J. \& Schurr, U. 2008. Impact of phosphorus mineral source (Al-P or Fe-P) and $\mathrm{pH}$ on cluster-root formation and carboxylate exudation in Lupinus albus L. Plant and Soil 304: 169-178. https://doi.org/10.1007/s11104-007-9535-7

Shi, Y., Byrne, D.H., Reed, D.W. \& Loeppert, R.H. 1993. Influence of bicarbonate level on iron chlorosis development and nutrient uptake of the peach rootstock. Journal of Plant Nutrition 16: 1675-1689. https://doi.org/10.1080/01904169309364642

Shirshova, L.T., Ghabbour, E.A. \& Davies, G. 2006. Spectroscopy characterizationo humic acid fractions isolated from soil using different extraction procedures. Geoderma 133: 204-216. https://doi.org/10.1016/j.geoderma.2005.07.007

Sierra, M.M.D., Fernandes, A.N. \& Szpoganicz, B. 2004. Influence of amide linkages on acidity determinations of humic substances. Testing with model-mixtures. Talanta 62: 687-693. https://doi.org/10.1016/j.talanta.2003.09.021

StatPoint 2000. Statgraphics Plus 5.1. Rockville, Maryland.

Stevenson, F.J. 1994. Humus chemistry: Genesis, composition, and reactions. New York: John Wiley and Sons. 512 p.

Tipping, E. 2002. Cation Binding by Humic Substances. Cambridge, UK: Cambridge University Press. https://doi.org/10.1017/CBO9780511535598

Trevisan, S., Francioso, O., Quaggiotti, S. \& Nardi, S. 2010. Humic substances biological activity at the plant-soil interface: from envionrmental aspects to molecular factors. Plant Signaling \& Behavior 5: 635-643. https://doi.org/10.4161/psb.5.6.11211

Violante, A., Barberis, E., Pigna, M. \& Boero, W. 2003. Factors affecting the formation, nature, and properties of iron precipitation products at the soil-root interface. Journal of Plant Nutrition 26: 1889-1908. https://doi.org/10.1081/PLN-120024252

Xu, Y.D., Yue, D.B., Zhu, Y. \& Nie, Y.F. 2006. Fractionation of disolved organic matter in matur landfill leachate and its recycling by ultrafiltration and evaporation combined processes. Chemosphere 64:903-911. https://doi.org/10.1016/j.chemosphere.2006.01.039

Zachara, J.M., Kukkadapu, R.K., Peretyazhko, T., Bowden, M., Wang, C., Kennedy, D.W., Moore, D. \& Arey, B. 2011. The mineralogic transformation of ferrihydrite induced by heterogeneous reaction with bioreduced anthraquinone disulfonate (AQDS) and the role of phosphate. Geochimica et Cosmochimica Acta 75: 6330-6349. https://doi.org/10.1016/j.gca.2011.06.030

Zanin, L., Tomasi, N., Cesco, S., Varanini, Z. \& Pinton, R. 2019. Humic substances contribute to plant iron nutrition acting as chelators and biostimulants. Frontier in Plant Science 10: 675. https://doi.org/10.3389/fpls.2019.00675

Zhu, W., Nan, Y., Huang, T. \& Wu, F. 2013. The mechanism, thermodynamic and kinetic characteristics of the microbial reduction of goethite mediated by anthraquinone-2-sulfonate. Geomicrobiology Journal 30: 928-940.

https://doi.org/10.1080/01490451.2013.791356 